\title{
An analytical study of FM listening practices and exposure to FM programs among FM listeners in Karnataka.
}

\author{
Niveditha.V \\ Asst Professor and Head of the Department, Department of Journalism SBRR Mahajana First Grade Collage \\ Jayalakshmipuram, Mysore
}

\begin{abstract}
Radio has always been part of our lives. It has also been a profitable business since the early days of broadcasting. Today, all sorts of digital devices have combined to create a 'self-media' environment that resituates radio, in the face of new challenges.

The study sought to analyse FM listening practices and the exposure to various FM programms among the FM listeners in Karnataka The study is based on systematic survey research method. The research attempts to formulate the problem of analysing FM listeners and their perceptions regarding their listening practices and the exposure

Following are the parameters used for the survey:

1. Place of listening FM Radio

2. Associates (Co-listeners) of FM radio

3. Duration of listening FM Radio

4. Discussion over FM Radio

5. Exposure to Red FM programmes

6. Exposure to Big FM programmes

7. Exposure to Radio Mirchi programmes

(CHISQUARE test is used to verify the following research hypotheses.)

Questionnaire and Interview methods were primarily used for the purpose of primary data collection. Besides this, formal observation and consultation were also adopted for the purpose of generating additional relevant information. Incidental sampling and stratified sampling methods were followed for the purpose of choosing the subject of the study.
\end{abstract}

Key words: Broadcasting, Digital devices, Listening Practices, Exposure, Incidental sampling, stratified sampling.

\section{Introduction:}

"Like in other countries around the world, Indians too rely on a combination of radio, television, movies, and music, besides devices like Internet-powered smart phones and portable music players for entertainment." Rabe T. Iyer, Business Head, 92.7 BIG FM.

FM Radio is a device that can influence to its listeners in worldwide areas. It has capacity to increase one's knowledge, ideas, and understanding on any issue while maintaining personal relationship with its transmission. It is a medium by which its listeners interact with their environmental subjects. It can also be noteworthy, such as bringing change into a person's attitudes, culture and can cause for social change. Social change is the process of fetching development in social structures that can make people learn the ways of living styles in a particular community circle related to cultures and traditions.

FM radio stations are one of the most popular entertainment mediums offering millions of Indians a great mix of shows. According to industry experts and analysts, there are 250-300 million radio users today. Radio even though many consider it an obsolete medium in this generation, still has its use. People may not hear it to receive news or to send signals but they hear it without even realizing it. Many broadcasters thought that maybe the time for Radio is over with the introduction of i-pod's and MP3 players but with the beginning of online radio, it is safe to assume that the Radio is making a comeback.

\section{Evolution of FM}

In 1934, much of the world was in the grip of the Great Depression. Unemployment was an epidemic, and many businesses struggled desperately to survive. One notable exception to these economic troubles, however, was the radio industry. Broadcasters in the US were making upwards of two billion dollars a year, and they owed much of their success to the innovations of a brilliant man named Edwin Armstrong. Twenty years earlier he had significantly improved the sensitivity and quality of radio receivers with his invention of the regenerative circuit in his junior year of college, and he went on to further improve them with his Super 
Regenerative circuit and Super Heterodyne receiver. These laid the foundation for the success of radio broadcasting-- in fact, almost any radio you buy today will still incorporate these innovations. But in 1933, Armstrong brought about an even more revolutionary change in the broadcasting business: FM radio.

\section{Evolution of FM Radio in India}

FM broadcasting began on 23 July 1977 in Chennai then Madras, and was expanded during the 1990s. In the mid-nineties, when India first experimented with private FM broadcasters, the small tourist destination of Goa was the fifth place in this country of one billion where private players got FM slots. The other four centers were the big metro cities: Delhi, Kolkata, Mumbai and Chennai. These were followed by stations in Bangalore, Hyderabad, Jaipur and Lucknow.

Phase 1: In 1993, the government sold airtime blocks on its FM channels in Madras, Mumbai, Delhi, Kolkata and Goa to private operators, who developed their own programme content.

Times FM (now Radio Mirchi) began operations in 1993 in Ahmedabad. Until 1993, All India Radio or AIR, a government undertaking, was the only radio broadcaster in India. The government then took the initiative to privatize the radio broadcasting sector. It sold airtime blocks on its FM channels in Indore, Hyderabad, Mumbai, Delhi, Kolkata, Vizag and Goa to private operators, who developed their own program content. The Times Group operated its brand, Times FM, till June 1998. After that, the government decided not to renew contracts given to private operators. In 2000, the government announced the auction of $108 \mathrm{FM}$ frequencies across India.

Radio City Bangalore is India's first private FM radio station and was started on July 3, 2001. It launched with presenters such as Rohit Barker, Darius Sunawala, JonzieKurian and Suresh Venkat.

Phase II: of FM licensing happened in 2006, where some 338 frequencies were offered of which about 237 were sold. While, the government may go for re-bidding of unsold frequencies.

Phase III: of FM licensing sees smaller towns and cities opening up for FM radio. Although they were allowed only $15 \%$ of the total allocated frequencies, Reliance and South Asia FM (Sun group) bid for most of the 91 cities.

\section{Review of Literature:}

Cohen (1996:37) examined the need for mobilizing communities for participation and empowerment in the modern society and observed that micro-media like FM radio, community radio; low power television centre, rural press, extension communication and other media were beneficial from participatory communication and development point of view. The scholar suggested that FM radio should be utilized for educational and development broadcasting rather than generating income from entertainment and advertisement programmes.

Leentvaar and Flint (1996:103) examined the capture effect in FM receivers in modern society and pointed out that FM radio captured the young generation of audience including women in the urban areas across the globe. The study revealed that FM radio played a limited role from public instruction, welfare and development points of view in modern society. The scholars suggested that FM radio owners and broadcasters should function with social concern and responsibility to reach out to the unreached and disadvantaged sections of society.

Franck (1998:56) examined the fight for micro radio centers in modern society and reported that privatization of FM radio brought about a new era of commercialization of broadcasting services. The scholar observed that FM radio had the capacity to educate and mobilize the masses at the grassroots level for various developmental endeavours. The scholar suggested that the structure and contents of FM radio stations should be reformed to provide people -friendly micro level broadcasting services.

Skinner (1998:170) examined the low power FM radio and reported that the attempts to privatize its FM channels ran into rough weather when private players bid heavily and most could not meet their commitments to pay the government the amounts they owed. The scholar suggested that effective regulations were essential to put FM radio stations in the right track and safeguard public interest in modern times.

Rudin (1999:159) examined the Eureka 147 from the point of view of digital diversity and noted that government had not placed any reasonable restrictions on the FM radio stations. The scholar further reported that FM radio stations were governed on the basis of economics of broadcasting rather than social developmental obligations. The scholar suggested that FM radio owners and broadcasters should function on the basis of humanitarian considerations in modern society.

Albiniak(2000:08) examined the style of functioning of modern FM radio stations and pointed out that FM radio stations posed serious challenges to public broadcasting institutions in modern times. The study revealed that FM radio industry had further growth opportunities in the new millennium. The scholar suggested that FM radio industry should collaborate and implement a measurement system that supports the growth of the industry on the basis of sound ethical and professional considerations. 
Fardon and Furness (2000:51) examined the African broadcasting culture and noted that modern radio industry was in transition due to several policy changes and technological developments. The study revealed that African broadcasting institutions functioned with a sense of social responsibility. The scholars cautioned that FM radio stations would lose credibility and prominence if they do not follow the sound principles of broadcasting management.

Hendy (2000:67) examined the political economy of radio in the digital age and reported that FM radio faced tough competition from the web radio which mainly catered to the niche audiences that were not satisfied with film songs played by most modern FM radio stations. The scholar further noted that FM radio stations were controlled by the market forces who were guided by the business considerations. The scholar suggested that FM radio stations should change their profile and performance to live up to the expectations of the audience.

\section{Research Methodology:}

The research paper is designed based on descriptive method of research. An attempt is made to 4examine the listening practices as well as the exposure of different FM programmes among the FM listeners in Karnataka. The research is carried out by using interview schedules and questionnaires to explore the listening practices and exposure to different FM programmes across the four major cities in Karnataka, i.e. Mysore, Bangalore, Mangalore and Gulbarga. Incidental sampling and Snow ball sampling methods are employed to identify the respondents. Sample size of the complete survey was 441(Mysore, Bangalore, Mangalore, and Gulbarga).The survey is conducted during the 2013-14.

One way ANOVA and one sample ' $t$ 'test statistics are taken as references to validate the research hypotheses.

Hypothesis 1:

\section{Research Hypotheses:}

$\mathrm{H}(0)$ : No significant difference among the FM listeners with regard to the listening practices.

$\mathrm{H}$ (1): There is a significant difference among FM listeners with regard to the FM listening practices.

Hypothesis: 2

$\mathrm{H}(0)$ : No significant difference among the FM listeners with regard to the exposure to FM programmes $\mathrm{H}$ (1): There is a significant difference among the FM listeners with regard to the exposure to FM programmes.

VI. Data Analysis and Interpretations

Table I:Demographic profile of the respondents

\begin{tabular}{|c|c|c|c|c|c|}
\hline a).Gender & Mysore & Bangalore & Mangalore & Gulbarga & Total \\
\hline Male & 79 & 48 & 51 & 46 & 224 \\
\hline Female & 63 & 51 & 49 & 54 & 217 \\
\hline
\end{tabular}

\begin{tabular}{|c|c|c|c|c|c|}
\hline b).Age(years) & Mysore & Bangalore & Mangalore & Gulbarga & Total \\
\hline $18-25$ & 39 & 20 & 40 & 42 & 141 \\
\hline $26-35$ & 39 & 43 & 25 & 35 & 142 \\
\hline $36-45$ & 39 & 30 & 20 & 17 & 106 \\
\hline $46<$ & 25 & 06 & 15 & 06 & 52 \\
\hline
\end{tabular}

\begin{tabular}{|c|c|c|c|c|c|}
\hline c).Education & Mysore & Bangalore & Mangalore & Gulbarga & Total \\
\hline SSLC & 45 & 25 & 13 & 22 & 105 \\
\hline PUC & 39 & 36 & 35 & 36 & 146 \\
\hline Degree & 39 & 27 & 34 & 38 & 138 \\
\hline PG & 19 & 11 & 18 & 04 & 52 \\
\hline
\end{tabular}

\begin{tabular}{|c|c|c|c|c|c|}
\hline d).Income & Mysore & Bangalore & Mangalore & Gulbarga & Total \\
\hline High & 19 & 02 & 19 & -- & 40 \\
\hline Medium & 80 & 35 & 41 & 20 & 176 \\
\hline Low & 43 & 62 & 40 & 80 & 225 \\
\hline
\end{tabular}

\begin{tabular}{|c|c|c|c|c|c|}
\hline f).Profession & Mysore & Bangalore & Mangalore & Gulbarga & Total \\
\hline Agriculture & 18 & 13 & 04 & 10 & 45 \\
\hline Business & 39 & 30 & 15 & 24 & 108 \\
\hline Service & 22 & 24 & 19 & 18 & 83 \\
\hline House wife & 25 & 16 & 23 & 13 & 77 \\
\hline Unemployed & 30 & 16 & 39 & 35 & 120 \\
\hline Others & 08 & --- & -- & -- & 08 \\
\hline
\end{tabular}


An analytical study of FM listening practices and exposure to FM programs among FM listeners in

Croan Bach Alpha reliability test statistic

\begin{tabular}{|c|l|c|c|c|c|}
\hline \multirow{2}{*}{ II. } & \multirow{2}{*}{ Exposure to FM programs } & \multicolumn{4}{|c|}{ Croan Bach Alpha } \\
\cline { 3 - 6 } & & $\begin{array}{c}\text { Mysore } \\
(\mathrm{n}=142)\end{array}$ & $\begin{array}{c}\text { Bangalore } \\
(\mathrm{n}=99)\end{array}$ & $\begin{array}{c}\text { Mangalore } \\
(\mathrm{n}=100)\end{array}$ & 0.810 \\
\hline 1 & Red FM & 0.516 & 0.687 & 0.782 & 0.523 \\
\hline 2 & Big FM & 0.721 & 0.546 & 0.866 & ---- \\
\hline 3 & Radio Mirchi & -- NA-- & 0.654 & - \\
\hline
\end{tabular}

\begin{tabular}{|c|c|c|c|c|c|c|c|c|c|c|c|c|}
\hline \multirow{2}{*}{\multicolumn{3}{|c|}{ VARIABLES }} & \multicolumn{2}{|c|}{ Mysore } & \multicolumn{2}{|c|}{ Gulbarga } & \multicolumn{2}{|c|}{ Bangalore } & \multicolumn{2}{|c|}{ Mangalore } & \multicolumn{2}{|c|}{ Total } \\
\hline & & & YES & NO & YES & $\mathrm{NO}$ & YES & $\mathrm{NO}$ & YES & NO & YES & $\mathrm{NO}$ \\
\hline \multirow{8}{*}{ 泾 } & \multirow{2}{*}{ Home } & $\mathrm{F}$ & 117 & 25 & 77 & 23 & 65 & 34 & 58 & 42 & 317 & 124 \\
\hline & & $\%$ & 27 & 6 & 17 & 5 & 15 & 8 & 13 & 10 & 72 & 28 \\
\hline & \multirow{2}{*}{$\begin{array}{l}\text { Work } \\
\text { place }\end{array}$} & $\mathrm{F}$ & 30 & 112 & 49 & 51 & 41 & 58 & 63 & 37 & 183 & 258 \\
\hline & & $\%$ & 7 & 25 & 11 & 12 & 9 & 13 & 14 & 8 & 41 & 59 \\
\hline & \multirow{2}{*}{ Travelling } & $\mathrm{F}$ & 100 & 42 & 53 & 47 & 71 & 28 & 63 & 37 & 287 & 154 \\
\hline & & $\%$ & 23 & 10 & 12 & 11 & 16 & 6 & 14 & 8 & 65 & 35 \\
\hline & \multirow{2}{*}{ Others } & $\mathrm{F}$ & 5 & 137 & 4 & 96 & 4 & 95 & 2 & 98 & 15 & 426 \\
\hline & & $\%$ & 1 & 31 & 1 & 22 & 1 & 22 & 0 & 22 & 3 & 97 \\
\hline
\end{tabular}

\begin{tabular}{|c|c|c|c|c|c|c|c|c|c|c|c|c|}
\hline & \multirow{2}{*}{\multicolumn{2}{|c|}{ VARIABLES }} & \multicolumn{2}{|c|}{ Mysore } & \multicolumn{2}{|c|}{ Gulbarga } & \multicolumn{2}{|c|}{ Bangalore } & \multicolumn{2}{|c|}{ Mangalore } & \multicolumn{2}{|c|}{ Total } \\
\hline & & & YES & $\mathrm{NO}$ & YES & $\mathrm{NO}$ & YES & $\mathrm{NO}$ & YES & $\mathrm{NO}$ & YES & $\mathrm{NO}$ \\
\hline \multirow{16}{*}{ 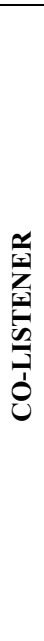 } & \multirow{2}{*}{ Alone } & $\mathrm{F}$ & 119 & 23 & 86 & 14 & 84 & 15 & 41 & 59 & 330 & 111 \\
\hline & & $\%$ & 27 & 5 & 20 & 3 & 19 & 3 & 9 & 13 & 75 & 25 \\
\hline & \multirow[t]{2}{*}{ Parents } & $\mathrm{F}$ & 10 & 132 & 25 & 75 & 16 & 83 & 32 & 68 & 83 & 358 \\
\hline & & $\%$ & 2 & 30 & 6 & 17 & 4 & 19 & 7 & 15 & 19 & 81 \\
\hline & \multirow[t]{2}{*}{ Friends } & $\mathrm{F}$ & 81 & 61 & 53 & 47 & 48 & 51 & 48 & 52 & 230 & 211 \\
\hline & & $\%$ & 18 & 14 & 12 & 11 & 11 & 12 & 11 & 12 & 52 & 48 \\
\hline & \multirow[t]{2}{*}{ Classmates } & $\mathrm{F}$ & 18 & 124 & 7 & 93 & 16 & 83 & 20 & 80 & 61 & 380 \\
\hline & & $\%$ & 4 & 28 & 2 & 21 & 4 & 19 & 5 & 18 & 14 & 86 \\
\hline & \multirow[t]{2}{*}{ Relatives } & $\mathrm{F}$ & 15 & 127 & 14 & 86 & 15 & 84 & 10 & 90 & 54 & 387 \\
\hline & & $\%$ & 3 & 29 & 3 & 20 & 3 & 19 & 2 & 20 & 12 & 88 \\
\hline & \multirow{2}{*}{$\begin{array}{l}\text { Fellow } \\
\text { workers }\end{array}$} & $\mathrm{F}$ & 17 & 125 & 24 & 76 & 23 & 76 & 18 & 82 & 82 & 359 \\
\hline & & $\%$ & 4 & 28 & 5 & 17 & 5 & 17 & 4 & 19 & 19 & 81 \\
\hline & \multirow{2}{*}{ Siblings } & $\mathrm{F}$ & 12 & 130 & 20 & 80 & 24 & 75 & 16 & 84 & 72 & 369 \\
\hline & & $\%$ & 3 & 29 & 5 & 18 & 5 & 17 & 4 & 19 & 16 & 84 \\
\hline & \multirow[t]{2}{*}{ Others } & $\mathrm{F}$ & 1 & 141 & 2 & 98 & 2 & 97 & 2 & 98 & 7 & 434 \\
\hline & & $\%$ & 0 & 32 & 0 & 22 & 0 & 22 & 0 & 22 & 2 & 98 \\
\hline
\end{tabular}

\begin{tabular}{|c|c|c|c|c|c|c|c|c|c|c|c|c|}
\hline \multirow{2}{*}{\multicolumn{3}{|c|}{ VARIABLES }} & \multicolumn{2}{|c|}{ Mysore } & \multicolumn{2}{|c|}{ Gulbarga } & \multicolumn{2}{|c|}{ Bangalore } & \multicolumn{2}{|c|}{ Mangalore } & \multicolumn{2}{|c|}{ Total } \\
\hline & & & YES & $\mathrm{NO}$ & YES & $\mathrm{NO}$ & YES & $\mathrm{NO}$ & YES & $\mathrm{NO}$ & YES & NO \\
\hline \multirow{10}{*}{ 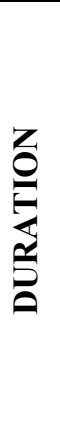 } & \multirow[t]{2}{*}{$<1$ Hour } & $\mathrm{F}$ & 21 & 121 & 9 & 91 & 12 & 87 & 21 & 79 & 63 & 378 \\
\hline & & $\%$ & 5 & 27 & 2 & 21 & 3 & 20 & 5 & 18 & 14 & 86 \\
\hline & \multirow{2}{*}{1 Hours } & $F$ & 29 & 113 & 19 & 81 & 20 & 79 & 20 & 80 & 88 & 353 \\
\hline & & $\%$ & 7 & 26 & 4 & 18 & 5 & 18 & 5 & 18 & 20 & 80 \\
\hline & \multirow[t]{2}{*}{2 Hours } & $\mathrm{F}$ & 70 & 72 & 41 & 59 & 45 & 54 & 41 & 59 & 197 & 244 \\
\hline & & $\%$ & 16 & 16 & 9 & 13 & 10 & 12 & 9 & 13 & 45 & 55 \\
\hline & \multirow{2}{*}{3 Hours } & $F$ & 19 & 123 & 20 & 80 & 36 & 63 & 20 & 80 & 95 & 346 \\
\hline & & $\%$ & 4 & 28 & 5 & 18 & 8 & 14 & 5 & 18 & 22 & 78 \\
\hline & \multirow{2}{*}{ More than $3 \mathrm{hr}$} & $\mathrm{F}$ & 6 & 136 & 21 & 79 & 49 & 50 & 7 & 93 & 83 & 358 \\
\hline & & $\%$ & 1 & 31 & 5 & 18 & 11 & 11 & 2 & 21 & 19 & 81 \\
\hline
\end{tabular}


An analytical study of FM listening practices and exposure to FM programs among FM listeners in

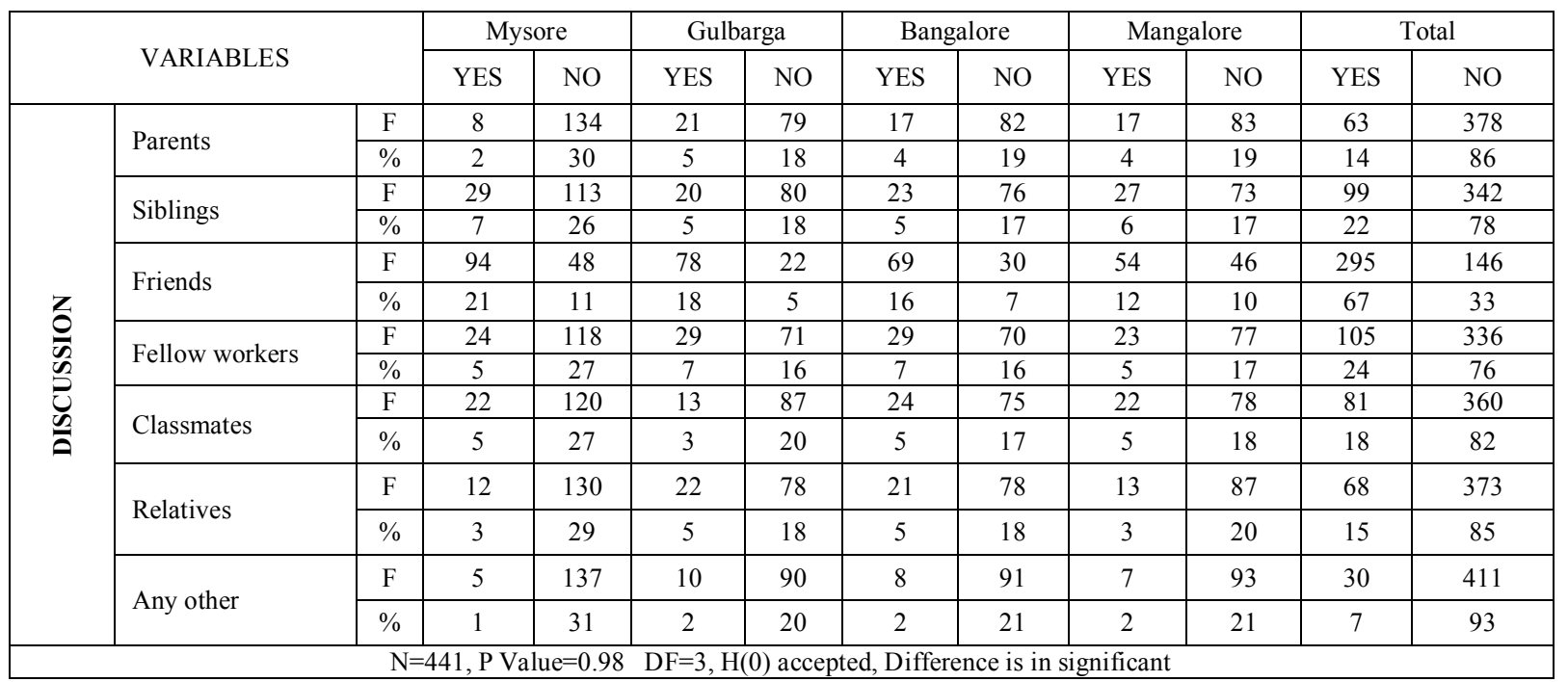

\begin{tabular}{|c|c|c|c|c|c|c|c|c|c|c|c|c|c|}
\hline \multirow{2}{*}{\multicolumn{3}{|c|}{ VII.VARIABLES }} & \multicolumn{2}{|c|}{ MYSORE } & \multicolumn{2}{|c|}{ GULBARGA } & \multicolumn{2}{|c|}{ BANGALORE } & \multicolumn{2}{|c|}{ MANGALORE } & \multicolumn{2}{|c|}{ TOTAL } & \multirow[b]{2}{*}{ T-Test statistic } \\
\hline & & & YES & $\mathrm{NO}$ & YES & $\mathrm{NO}$ & YES & NO & YES & $\mathrm{NO}$ & YES & $\mathrm{NO}$ & \\
\hline \multirow{40}{*}{ 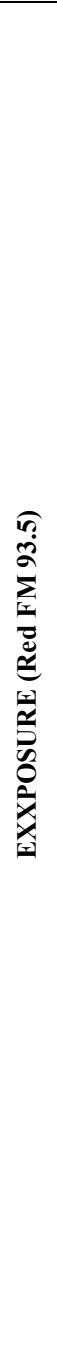 } & \multirow{2}{*}{ Omkara } & $\mathrm{F}$ & 55 & 87 & 42 & 85 & NA & NA & 41 & 59 & 138 & 231 & \multirow{2}{*}{$\begin{array}{c}\mathrm{P}=0.36 \text {,Insignificant } \mathrm{H} \\
\text { 0):Accepted }\end{array}$} \\
\hline & & $\%$ & 12 & 20 & 10 & 19 & 0 & 0 & 9 & 13 & 31 & 52 & \\
\hline & \multirow{2}{*}{ Namaskara } & $\mathrm{F}$ & 88 & 54 & 75 & 25 & NA & NA & 74 & 26 & 237 & 105 & \multirow{2}{*}{$\begin{array}{c}\mathrm{P}=0.2 \text {,Insignificant } \\
\mathrm{H}(0) \text { : Accepted. }\end{array}$} \\
\hline & & $\%$ & 20 & 12 & 17 & 6 & 0 & 0 & 17 & 6 & 54 & 24 & \\
\hline & \multirow{2}{*}{$\begin{array}{c}\text { Super Hits } \\
\text { masala }\end{array}$} & F & 57 & 85 & 60 & 40 & 38 & 61 & 57 & 74 & 212 & 260 & \multirow{2}{*}{$\begin{array}{c}\mathrm{P}=0.31, \text { Insignificant } \\
\mathrm{H}(0) \text { : Accepted }\end{array}$} \\
\hline & & $\%$ & 13 & 19 & 14 & 9 & 9 & 14 & 13 & 17 & 48 & 59 & \\
\hline & \multirow{2}{*}{$\begin{array}{l}\text { Music } \\
\text { Adda }\end{array}$} & F & 89 & 53 & 54 & 47 & NA & NA & 53 & 47 & 196 & 147 & \multirow{2}{*}{$\begin{array}{c}\mathrm{P}=0.60, \text { Insignificant } \\
\mathrm{H}(0) \text { :Accepted }\end{array}$} \\
\hline & & $\%$ & 20 & 12 & 12 & 11 & 0 & 0 & 12 & 11 & 44 & 33 & \\
\hline & \multirow{2}{*}{$\begin{array}{l}\text { Bindass } \\
\text { Bajaisi }\end{array}$} & $\mathrm{F}$ & 97 & 45 & 48 & 52 & NA & NA & 59 & 41 & 204 & 138 & \multirow{2}{*}{$\begin{array}{c}\mathrm{P}=0.50, \text { Insignificant } \\
\mathrm{H}(0) \text { :Accepted }\end{array}$} \\
\hline & & $\%$ & 22 & 10 & 11 & 12 & 0 & 0 & 13 & 9 & 46 & 31 & \\
\hline & \multirow{2}{*}{$\begin{array}{l}\text { Just Maath } \\
\text { Maathali }\end{array}$} & F & 55 & 87 & NA & NA & NA & NA & NA & NA & 55 & 87 & \multirow{2}{*}{$\begin{array}{c}\mathrm{P}=0.65, \text { Insignificant } \\
\mathrm{H}(0) \text { : Accepted }\end{array}$} \\
\hline & & $\%$ & 12 & 20 & 0 & 0 & 0 & 0 & 0 & 0 & 12 & 20 & \\
\hline & \multirow{2}{*}{$\begin{array}{l}\text { Super Hits } \\
\text { Top } 30 \\
\end{array}$} & $\mathrm{~F}$ & 72 & 70 & 66 & 34 & 25 & 74 & 45 & 55 & 208 & 233 & \\
\hline & & $\%$ & 16 & 16 & 15 & 8 & 6 & 17 & 10 & 12 & 47 & 53 & H (0):Accepted \\
\hline & Love Story & $\mathrm{F}$ & 79 & 63 & NA & NA & NA & NA & 53 & 47 & 132 & 110 & $\mathrm{P}=0.84$ Insignificant \\
\hline & Dot Com & $\%$ & 18 & 14 & 0 & 0 & 0 & 0 & 12 & 11 & 30 & 25 & H (0):Accepted \\
\hline & Character & $\mathrm{F}$ & 73 & 69 & NA & NA & NA & NA & NA & NA & 73 & 69 & $\mathrm{P}=0.87$, Insignificant \\
\hline & Capsule & $\%$ & 17 & 16 & 0 & 0 & 0 & 0 & 0 & 0 & 17 & 16 & H (0):Accepted \\
\hline & $\mathrm{B} 2 \mathrm{~B}$ & $\mathrm{~F}$ & 37 & 105 & NA & NA & NA & NA & NA & NA & 37 & 105 & $\mathrm{P}=0.56$, Insignificant \\
\hline & $\mathrm{D} \angle \mathrm{D}$ & $\%$ & 8 & 24 & 0 & 0 & 0 & 0 & 0 & 0 & 8 & 24 & H (0):Accepted \\
\hline & B2B(Retro & $\mathrm{F}$ & 34 & 108 & NA & NA & 21 & 78 & NA & NA & 55 & 186 & $\mathrm{P}=0.29$, Insignificant \\
\hline & Melody Mix) & $\%$ & 8 & 24 & 0 & 0 & 5 & 18 & 0 & 0 & 12 & 42 & H (0):Accepted \\
\hline & Morning & F & NA & NA & NA & NA & 24 & 75 & NA & NA & 24 & 75 & $\mathrm{P}=0.54$, Insignificant \\
\hline & Manthra & $\%$ & 0 & 0 & 0 & 0 & 5 & 17 & 0 & 0 & 5 & 17 & H (0):Accepted \\
\hline & Morning & $\mathrm{F}$ & NA & NA & $\mathrm{NA}$ & NA & 31 & 68 & $\mathrm{NA}$ & NA & 31 & 68 & $\mathrm{P}=0.63$, Insignificant \\
\hline & No 1 & $\%$ & 0 & 0 & 0 & 0 & 7 & 15 & 0 & 0 & 7 & 15 & H (0):Accepted \\
\hline & Happy & $\mathrm{F}$ & NA & NA & NA & NA & 28 & 71 & NA & NA & 28 & 71 & $\mathrm{P}=0.59$, Insignificant \\
\hline & Hours & $\%$ & 0 & 0 & 0 & 0 & 6 & 16 & 0 & 0 & 6 & 16 & H (0):Accepted \\
\hline & 935 Meter & $\mathrm{F}$ & NA & NA & NA & NA & 19 & 80 & NA & NA & 19 & 80 & $\mathrm{P}=0.48$, Insignificant \\
\hline & Down & $\%$ & 0 & 0 & 0 & 0 & 4 & 18 & 0 & 0 & 4 & 18 & H (0):Accepted \\
\hline & Red & $\mathrm{F}$ & NA & NA & NA & NA & 29 & 70 & NA & NA & 29 & 70 & $\mathrm{P}=0.60$, Insignificant \\
\hline & Rewind & $\%$ & 0 & 0 & 0 & 0 & 7 & 16 & 0 & 0 & 7 & 16 & H (0):Accepted \\
\hline & TODU & $\mathrm{F}$ & NA & $\mathrm{NA}$ & $\mathrm{NA}$ & NA & 17 & 82 & NA & NA & 17 & 82 & $\mathrm{P}=0.46$, Insignificant \\
\hline & Nights & $\%$ & 0 & 0 & 0 & 0 & 4 & 19 & 0 & 0 & 4 & 19 & H (0):Accepted \\
\hline & SaviSavi & $\mathrm{F}$ & NA & NA & 62 & 38 & NA & NA & 70 & 30 & 132 & 68 & $\mathrm{P}=0.48$, Insignificant \\
\hline & Nenapu & $\%$ & 0 & 0 & 14 & 9 & 0 & 0 & 16 & 7 & 30 & 15 & H (0):Accepted \\
\hline & Star & $\mathrm{F}$ & NA & NA & NA & NA & NA & NA & 22 & 78 & 22 & 78 & $\mathrm{P}=0.51$, Insignificant \\
\hline & attack & $\%$ & 0 & 0 & 0 & 0 & 0 & 0 & 5 & 18 & 5 & 18 & H (0):Accepted \\
\hline & KUDLA & $\mathrm{F}$ & NA & NA & NA & NA & NA & NA & 50 & 50 & 50 & 50 & $\mathrm{P}=1.0$, Insignificant \\
\hline & EXPRESS & $\%$ & 0 & 0 & 0 & 0 & 0 & 0 & 11 & 11 & 11 & 11 & H (0):Accepted \\
\hline
\end{tabular}




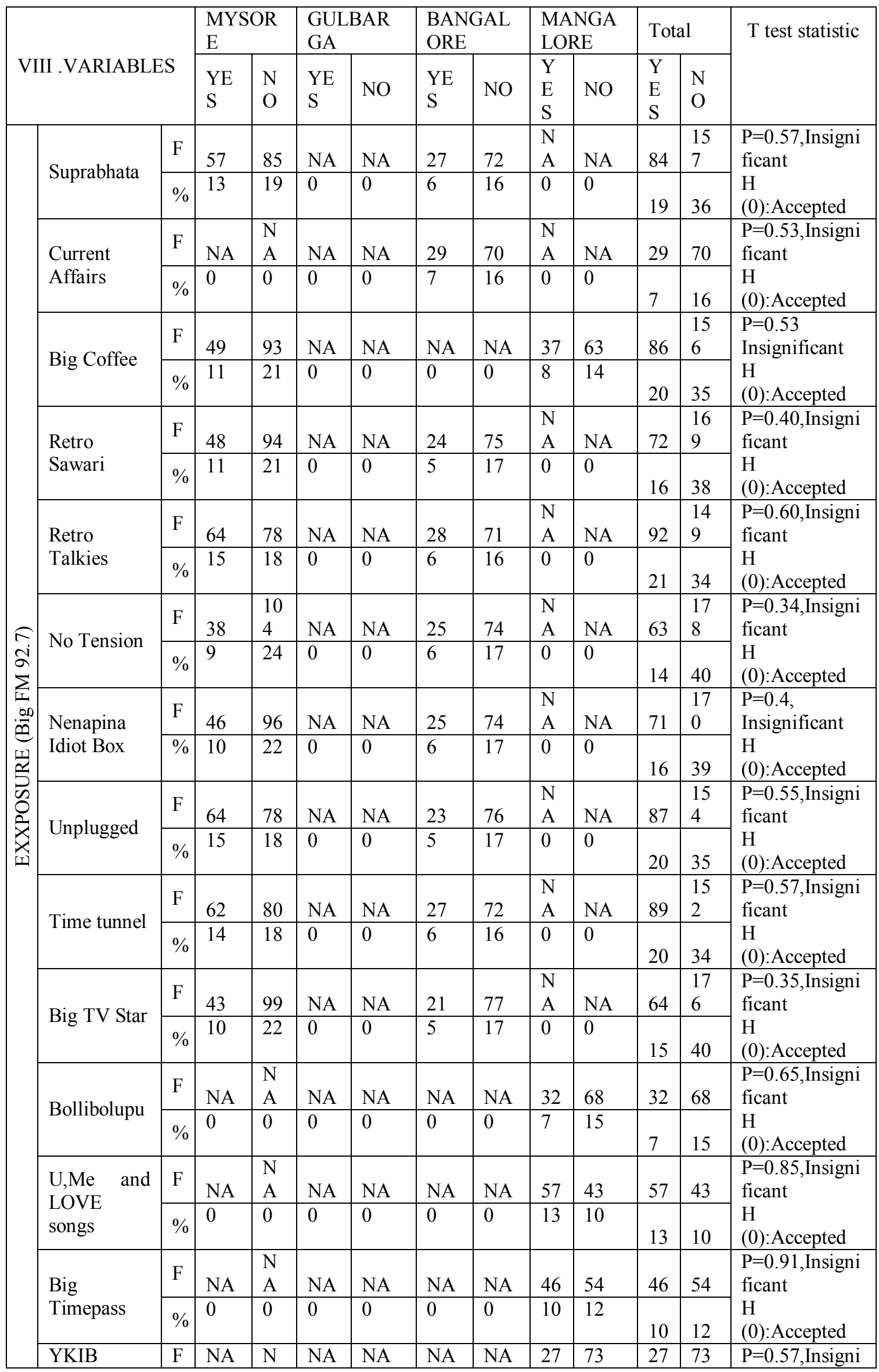


An analytical study of FM listening practices and exposure to FM programs among FM listeners in

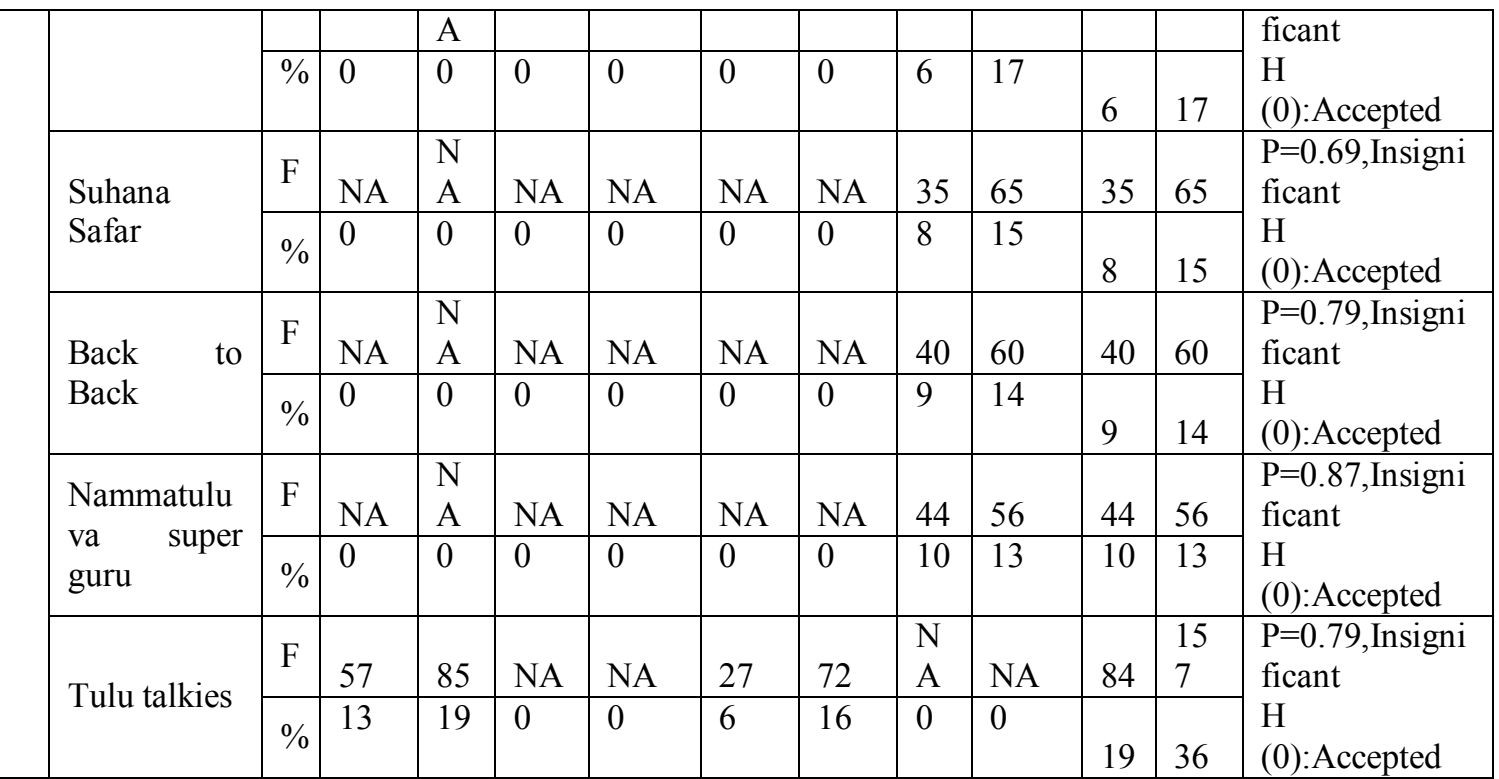

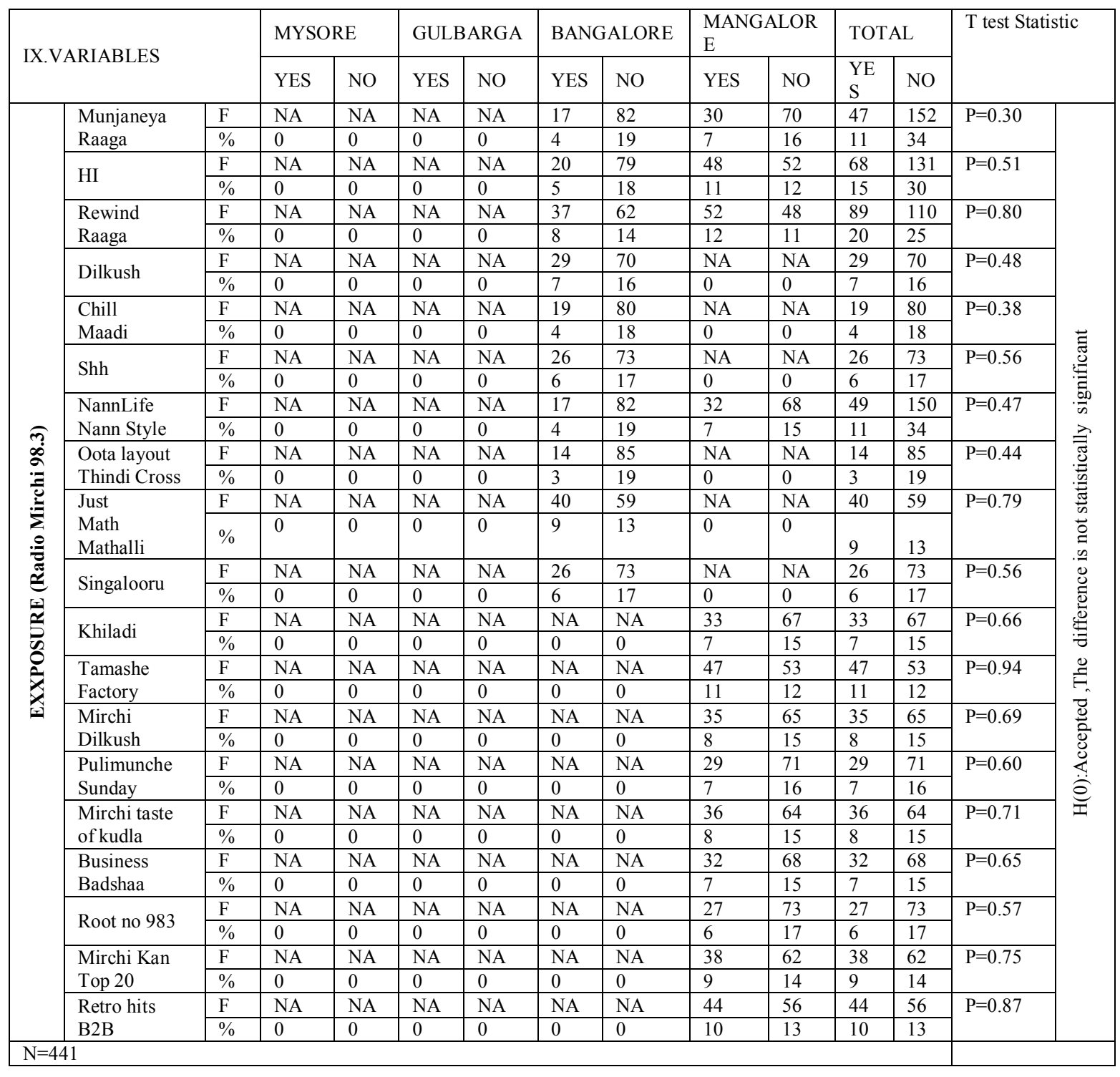




\section{Conclusions and Discussion for further research:}

$\rightarrow$ The socio demographic variables of the survey are represented in the tables from 1a to 1e.The findings from the statistical representation supports that the data for the purpose of the survey is selected across a wide cross section of the FM listening community.

$\rightarrow$ Table II represents the value of Croan bach alpha reliability in order to verify the reliability/validity of the set parameters considered for the survey.The reliability test statistic values for Red FM Mysore, Gulbarga and Big FM Bangalore are found to be poor, which needs to be addressed by the researchers by defining more valid questionnaire and with further large sample size.

$\rightarrow$ Table III represents number FM listeners and their place of listening across Mysore, Bangalore, Mangalore and Gulbarga districts. The Chi-square analysis supports the statement that there is no difference among the place of listening across the state of Karnataka, and in this regard the null hypothesis found to accepted and therefore the difference is stastically in significant. Among the FM listeners in Karnataka $72 \%$ of the FM listeners prefers to listen at their homes, and $65 \%$ of the listeners prefer to listen FM during travelling.

$\rightarrow$ Table IV examines the trend FM listeners with respect to associate/co-listeners, who can be the likely partners at the time of FM listening. The trend with respect to other partners such as parents, family members, and friends seems to be not encouraging much, but rather the FM listeners are solitary (alone) in nature. Approximately $75 \%$ of the FM listeners across the state are preferred to listen FM alone.Therefore as a researcher I can suggest that the FM establishment can revive its broadcasting strategy such that it can transform into overall family entertainment medium and thus to maximise its reach.In this regard the null hypothesis found to be accepted and therefore the difference is stastically in significant.

$\rightarrow$ Table V examines the trend of FM listening duration across the state. The chi-square analysis supports that there is no significant difference in relation the FM listening duration across the state. The table reads that only $45 \%$ of the FM listeners across the state listen for duration of 2 hours per day.

$\rightarrow$ Table VI examines the trend of FM discussion with the different associates of the society. The finding from the table is that $67 \%$ of the FM listeners discusses with their friends. The most important revelation is that only $14 \%$ of the listeners discusses with their parents where as $22 \%$ and $15 \%$ of the listeners discusses with siblings and relatives. In this regard I would like to suggest that the FM programmes needs an amount of family touch so that social recognition for the FM programmes can be enhanced.The chi-square analysis supports that there is no significant difference in relation the FM discussion pattern across the state.

$\rightarrow$ Table VII, VIII, IX examines the significant difference among the FM listeners across the state in relation to the exposure to the FM programmes such as Red FM, Big FM, and Radio Mirchi. In this regard the null hypothesis stands accepted, supporting the fact the exposure to FM programmes is symmetrically distributed with respect to the respective FM listeners of the state. The differences in this regard are found to be statistically in significant.

\section{Limitations:}

$\rightarrow$ Sample size of 441 for the whole state of Karnataka is not a representative sample, which creates a greater influence on sampling error.

$\rightarrow$ Rural parts of Karnataka are not considered for the survey.

$\rightarrow$ Scope of FM listening and its impact on socio-economic development is not considered for analysis and interpretation.

$\rightarrow$ The impact of FM listening on the communication and language awareness/improvement is not studied.

\section{Bibliography:}

[1]. Abbas, Azmat (2004) FM 103 forced off airwaves, The Herald, Dec 10, p 38.

[2]. Abellonosa, Henry J., Felisa Sheila T.Escalona,Ma.MillizaA.Lavanza,YvesT.Maagad,NikkoP.Quinonez,ChucilleB.Quipanes, and Hannah Grace D.Sy,(2011) The Effectiveness of Tri-Media Advertising Campaign for Enrolment of Liceo de Cagayan University,

[3]. Aggrawal, VirBala and V.S.Gupta (2001) Handbook of Journalism and Mass Communication, New Delhi: Concept Publishing Company.

[4]. Agrawal, Binod C (2011) Youth, the Indian Listeners of Radio: Some Observations, Paper presented in the RadioAsia2011 Conference, February 21-23, New Delhi, India.

[5]. Agrawal, Binod C and Raghaviah, Shalini (2006) Indian Public Service Broadcasting and Changing Perspectives, In Public Service Broadcasting in the Age of Globalization. eds. Indrajit Banerjee and KalingaSeveviratne; pp 149-164. Singapore: AMIC and Nanyang Technological University AnnymousNd Using Radio to Reach Youth Markets: RAB Guide. www.rajaz.co.uk

[6]. Ahmad, ZhahzadaIrfan (2003) FM breaks Through, Daily the News on Sunday, June, 15 p: 28.

[7]. Ala-Fossi, M and Jauert, P (2006) Nordic radio in the digital age. In U. Carlsson (Ed.), Nordic Media trends 9: Radio, TV \& Internet in the Nordic countries. Meeting the challenges of new media technology, Göteborg: Nordicom, pp 65-87 
[8]. Albiniak, P (2000) LPFM Battle Lines Drawn, Broadcasting and Cable, 7(8):721-730

[9]. Anand, Manish, Edmund B. Nightingale, and Jason Flinn (2005) Self-tuning wireless network power management. Wireless Networks, 11(1):451-469.

[10]. Ananthi, N (2012) Emerging Paradigms in Marketing: A Study on the FM Radio Market in Chennai City,www.ananthi.ethirajcollege@gmail.com 